\title{
ДИАГНОСТИЧЕСКОЕ ИССЛЕДОВАНИЕ ФОРМИРОВАНИЯ ИНОЯЗЫЧНОЙ КОММУНИКАЦИИ ОФИЦЕРОВ СУХОПУТНЫХ ВОЙСК: ОРГАНИЗАЦИЯ И ПРИНЦИПЫ
}

\section{DIAGNOSTIC RESEARCH OF THE FORMATION OF FOREIGN LANGUAGE COMMUNICATION OF ARMY OFFICERS: ORGANIZATION AND PRINCIPLES}

V. Bikbaev

Summary: The article deals with the mechanism of forming a diagnostic study of foreign language communication of An army officer. It is noted that the diagnostic study of foreign language communication of an Army officer at the present stage of military construction is of a socio-pedagogical nature and is based on a comprehensive analysis of the processes of formation of foreign language communication within the professional development of officers. The principles of pedagogical research are defined and partially disclosed, to which certain requirements are imposed in practical activities during the organization of diagnostics of foreign language communication of officers of the Land forces of the Armed Forces of the Russian Federation.

Keywords: diagnostic research, foreign language communication, professional development, principles of pedagogical research.

\author{
Бикбаев Вадим Манцурович \\ К.полит.н., доцент, Новосибирское высшее военное \\ командное училище \\ vadim_bikbaev@mail.ru
}

Аннотация: В статье рассматривается механизм формирования диагностического исследования иноязычной коммуникации офицера Сухопутных войск. Отмечается, что диагностическое исследование иноязычной коммуникации офицера Сухопутных войск на современном этапе военного строительства носит социально-педагогический характер и основано на всестороннем анализе процессов формирования иноязычной коммуникации в рамках профессионального становления офицеров. Определены и частично раскрыты принципы педагогического исследования и требования, которые к ним предъявляются в практической деятельности в процессе организации диагностики иноязычной коммуникации офицеров Сухопутных войск Вооруженных Сил Российской Федерации.

Ключевые слова: диагностическое исследование, иноязычная коммуникация, профессиональное становление, принципы педагогического исследования.

чаще всего понимают создание системы регламентов: правил, норм, ограничений, распределений полномочий и ответственности, механизмов управления и информационного обмена, задания исходных организационных позиций до исследования.

В настоящее время в условиях глобализации экономики и усиления конкуренции в социальной и экономической областях ряд исследователей рассматривают модели и методы организационной диагностики в вышеуказанных областях главным образом в целях минимизации финансовых затрат и экономических рисков.

В частности, организационную диагностику авторы понимают как постоянный и систематический сбор и анализ информации о состоянии деятельности учреждения или организации с целью выявления проблем ее функционирования, а также определения путей и резервов для их преодоления путем применения концептуальных моделей и различных методов.[5,11, 12,13]

Заслуживает внимания тезис С.А. Липатова. Ученый утверждает, что недостаточно просто определить, что происходит в организации. Результатом диагности-

Под термином «организация исследования» ученые 
ки, по его мнению, должны быть специфические рекомендации по изменениям в ней.

В тоже время, следует отметить точку зрения автора о том, что диагностическое исследование от научного отличает внимание к эмпирической целостности объекта и его индивидуальным различиям. Диагностический подход, по мнению С.А. Липатова, ориентирован не на поиск универсальных закономерностей и типизацию проблем организаций, а на выявление специфических проблем конкретной организации, а также на поиск путей их решения в условиях этой организации. [6]

Как мы видим, авторы в целом дают оценку организационному уровню и в некоторой степени разделяют диагностическое исследование от научного, а также отождествляют понятие «организация» (то есть учреждение) с самой деятельностью данной организации (учреждения), что применительно к нашему исследованию контрпродуктивно.

На наш взгляд, диагностическое исследование иноязычной коммуникации офицера Сухопутных войск на современном этапе военного строительства носит социально-педагогический характер, что обусловлено поиском возможных решений данной проблемы на основе всестороннего анализа процессов формирования иноязычной коммуникации в рамках профессионального становления офицеров.

Ряд исследователей рассматривают организационную диагностику как разновидность социальной диагностики, $[7,9]$ под которой в данном случае понимается деятельность по описанию состояния объекта (социальной системы) с целью выявления проблем (противоречий) его функционирования, а также определения породивших их причин и факторов [10].

В.А. Сластенин и другие исследователи [8] рассматривают организацию педагогических исследований как уровень педагогических технологий.

Следует отметить, что в рамках практической деятельности организации также требует решения ряда вопросов, связанных с научным поиском, основными признаками уровня качества которого являются принципы теоретической и практической значимости, а также новаторства с учетом конкретной ситуации, собственной гипотезы и научной интуиции.

На наш взгляд, организация диагностического исследования обеспечивает проведение исследования в рамках нормативно-правовой базы военной службы, выход за которые делает его принципиально невозможным. В то же время, она создает условия выполнения общепринятых правил педагогических исследований, без ко- торых результаты диагностики не могут быть признаны. Методология диагностического исследования без определения его организационных основ, которые можно достичь путем научного поиска, остается неполной.

Следует подчеркнуть, что поиск методологии сопряжен с решением ряда организационно-технических вопросов и процедур, основными из которых являются анализ исходных требований к организации исследования, общая характеристика содержания исследовательской программы, анализ статистических данных и др.

Профессиональное становление офицера - глубоко индивидуальный процесс. Вместе с тем, в совокупности индивидуальных процессов существуют сходные тенденции, в том числе и такие, которые характеризуют запрос по языковой подготовке, непрерывному профессиональному образованию и поддержке мероприятий, направленных на повышение языкового уровня офицера в рамках самообразования. Вследствие этого формирование иноязычной коммуникации выступает в качестве одной из основных тенденций профессионального становления офицера на современном этапе.

В диагностике иноязычной коммуникации офицеров Сухопутных войск Вооруженных Сил Российской Федерации следует определять регламенты и формировать исследовательские программы не только ориентируясь на цели исследования, но и учитывая сложившиеся в науке и практике традиционные и не подлежащие сомнению принципы педагогического исследования.

Особо следует отметить выдвинутые В.И. Загвязинским и Р. Атахановым [3] принципы педагогического исследования, к которым в практической деятельности в процессе организации диагностики иноязычной коммуникации офицеров Сухопутных войск Вооруженных Сил Российской Федерации предъявляются определенные требования.

Принцип объективности предполагает исключение субъективизма и одностороннего подхода в анализе и оценке фактов и выражается во всестороннем учете порождающих то или иное явление условий, в которых они развиваются, а также в адекватности самих исследовательских подходов и средств, позволяющих получить истинные знания об объекте исследования. [3, с.40]

Следует отметить, что как процессы формирования и развития иноязычной коммуникации, так и проблемы и трудности профессионального становления офицера носят субъективный характер.

Применительно к нашему исследованию необходим результат, который, по мнению И.А. Зимней, характеризует черты и тенденции развития максимально лишен- 
ного субъективных признаков так называемого совокупного субъекта образования. [4]

В.С. Аванесов, в свою очередь, указывал, что в педагогическом измерении объективное часто пересекается с субъективным, вследствие чего пессимизм относительно возможности достижения полностью объективных педагогических измерений имеет основание [1].

Как показывает практика, проблема объективности обострилась в педагогике в связи с чрезмерным распространением якобы изначально объективных тестовых методик и походов к оценке личности (системы контроля знаний, критерии оценки знаний обучаемых и др.), а также появлением объектов измерений, объединяющих признаки различной природы и уровня сложности, в том числе навыков, умений и компетенций.

На наш взгляд, в процессе профессионального становления в рамках осуществления иноязычной коммуникации на ее различных этапах происходит тесное взаимодействие объективного и субъективного факторов, преобладание которых зачастую трудно определить.

Для объективной оценки диагностического исследования иноязычной коммуникации, по мнению В.С. Аванесова, может быть сформулировано организационное требование предъявления измерительной модели для каждого оцениваемого признака.

По мнению ученого, в опытно-экспериментальной базе создаются исследовательские инфраструктуры, осуществляющие измерения без участия испытуемых, которые подключается только на этапе обобщений и выводов. Измерительная (диагностическая модель) предполагает как обязательные проверки надежности, адекватности и достоверности лингводидактических материалов, так и точности измерений с использованием различных программных проектов.

Данная модель основывается на теоретических представлениях о природе и проявлениях того или иного признака, в зависимости от которых избираются несколько перекрестных методов и средств измерения, отвечающие целям диагностического исследования.

Мы придерживаемся точки зрения В.С. Аванесова, который измерял проявляющиеся рамках профессиональной деятельности военнослужащих как явные признаки иноязычной коммуникации, так и скрытые ее формы посредством тестовых методик.

\section{Принцип сущностного анализа.}

На наш взгляд, соблюдение данного принципа в рамках диагностического исследования будет основано на представлении иноязычной коммуникации как постоянно развивающемся явлении. При этом в ходе анализа результатов первостепенное значение приобретают тенденции и прогнозы развития с учетом рассмотрения актуального состояния, а причины, факторы и актуальное состояние, тенденции и прогнозы развития составляют полный диагноз иноязычной коммуникации офицера сухопутных войск. В.И. Загвязинский и Р. Атаханов, во исполнение принципа сущностного анализа выдвинули требование учета непрерывного изменения объекта исследования.

По мнению ученых, принцип сущностного анализа предполагает движение исследовательской мысли от описания к объяснению, далее - к прогнозированию развития педагогических явлений и процессов. [3, с.41]

Следующим требованием данного принципа является выявление основных факторов изменений, что особенно проявляется при оценке образовательных процессов иноязычной коммуникации офицера Сухопутных войск и системы управления, оказывающей сильное влияние на процессы формирования и развития иноязычной коммуникации офицера.

Особенно, на наш взгляд, следует отметить третье требование - противоречивости исследуемого явления.

Оно актуально в связи с тем, что движущие силы, механизмы развития, противоречия и кризисные явления в рамках профессионального становления офицера Сухопутных войск прямо или косвенно связаны с формированием иноязычной коммуникации.

На наш взгляд, вышеуказанные требования совершенно справедливы. Учитывая механизмы формирования, развития и состояния иноязычной коммуникации офицеров Сухопутных войск, мы будем придерживаться их в дальнейшем исследовании.

Генетический принцип (или принцип единства логического и исторического), согласно которому изучаемые факты и явления должны рассматриваться с учетом условий его происхождения, развития, а также выявления моментов смены одного уровня функционирования качественно иным. [3, с.43]

При реализации данного принципа в диагностике иноязычной коммуникации офицера Сухопутных войск уделяется большое внимание причинно-следственным связям и факторам, обусловливающим актуальное состояние исследуемого явления.

На наш взгляд, для осуществления двух вышеперечисленных принципов применительно к диагностике иноязычной коммуникации необходимо сочетание 
историко-генетического, актуального и прогностического планов диагностического исследования.

Принцип концептуального единства исследования, который «внутренне противоречив, но представляет единство определенного, принятого как верное, и неопределенного, изменчивого, без которого исследователю не удается осуществить единство и логическую непротиворечивость подходов и оценок, он неизбежно соскальзывает на позиции эклектики». [3, с.44]

На наш взгляд, в процессе языковой подготовки в рамках профессионального становления офицера Сухопутных войск и осуществления иноязычной коммуни- кации в ходе повседневной жизнедеятельности данный принцип, как показывает практика, приобретает особую актуальность.

Таким образом, диагностика формирования иноязычной коммуникации офицера Сухопутных войск проводится согласно принципам научного исследования, результаты и методы которого должны быть взаимоприемлемыми как для объекта исследования с целью объективного решения проблем и трудностей профессионального становления реципиентов, так и для исследователей, осуществляющих диагностику с учетом причинно-следственных связей и факторов, обусловливающих актуальное состояние исследуемого явления.

ЛИТЕРАТУРА

1. Аванесов, В.С. Теория и методика педагогических измерений (материалы публикаций) / В.С. Аванесов // ЦТ и МКо УГтУ-упИ, 2005. - режим доступа: http://www.charko.narod.ru/tekst/biblio/Avanesov_Teoriya_i_metod_ped_izmer.pdf (дата обращения 18.12.2019).

2. Большая Советская Энциклопедия. В 30 томах. Т.18. - М.: Советская Энциклопедия, 1974. - 632 с.

3. Загвязинский, В.И., Атаханов, Р. Методология и методы психолого-педагогического исследования / В.И. Загвязинский, Р. Атаханов. - М.: Академия, 2005. $-208 c$.

4. Зимняя, И.А. Педагогическая психология / И.А. Зимняя. - М.: Логос, 2000. - 384 с.

5. Липатов С.А. Методы социально-психологической диагностики организаций // Введение в практическую социальную психологию / Под ред. Ю.М. Жукова, Л.А. Петровской, О.В. Соловьевой. - М., 1994.

6. Липатов С.А. Методы практической социальной психологии: Диагностика. Консультирование. Тренинг: Учебное пособие для вузов / Под ред. Ю.М. Жукова. - М.: Аспект Пресс, 2004. с. 48-68.

7. Пригожин, А.И. Современная социология организаций / А.Н. Пригожин. - М.: «Интерпракс», 1995. - 295 с.

8. Сластенин, В.А. и др. Педагогика / В.А. Сластенин, И.Ф. Исаев, Е.Н. Шиянов. - М.: Академия, 2002. - 576 с.

9. Щербина, В.В. Средства социологической диагностики в системе управления / В. В. Щербина.МГУ им. М. В. Ломоносова, Социол. фак. - М.: Изд-во МГу, 1993. $-116 \mathrm{c}$.

10. Щербина В.В. Социологическая диагностика и социальная инженерия // Социальная инженерия: В 2-х частях. Часть 1: Теоретико-методологические проблемы: Курс лекций / Под ред. Ю.М. Резника, В.В. Щербины. - М., 1994.

11. Burke W.W. Organization development: Principles and practice. - Boston, Toronto, 1982.

12. Harrison, M. I. Diagnosing organizations: Methods, models, and processes. - Newbury Park, 1994.

13. Nadler, D.A., Tushman, M.L. A diagnostic model for organization behavior // Perspectives on behavior in organizations / Ed. by J.R. Hackman; E.E. Lawler; L.W. Porter. - N.Y., 1977. 